University of Wollongong

Research Online

Australian Institute for Innovative Materials -

Papers

Australian Institute for Innovative Materials

2012

Methane activation on Fe4 cluster: a density functional theory study

Qiao Sun

University of Queensland

Zhen Li

University of Wollongong, zhenl@uow.edu.au

Meng Wang

East China University of Science and Technology

Aijun Du

University of Queensland

Sean C. Smith

University of Queensland

Follow this and additional works at: https://ro.uow.edu.au/aiimpapers

Part of the Engineering Commons, and the Physical Sciences and Mathematics Commons

Research Online is the open access institutional repository for the University of Wollongong. For further information contact the UOW Library: research-pubs@uow.edu.au 


\title{
Methane activation on Fe4 cluster: a density functional theory study
}

\author{
Abstract \\ We report a comprehensive theoretical study on reaction of methane by $\mathrm{Fe}_{4}$ cluster. This Letter gains \\ insight into the mechanism of the reaction and indicate the $\mathrm{Fe}_{4}$ cluster has strong catalytic effect on the \\ activation reaction of methane. In detail, the results show the cleavage of the first $\mathrm{C}-\mathrm{H}$ bond is both an \\ energetically and kinetically favourable process and the breaking of the second $\mathrm{C}-\mathrm{H}$ is the rate- \\ determining step. Moreover, our Letter demonstrates that the different cluster size of iron can not only \\ determine the catalytic activity of methane but also control the product selectivity.

\section{Keywords} \\ activation, methane, cluster, density, functional, theory, study, fe4 \\ Disciplines \\ Engineering | Physical Sciences and Mathematics

\section{Publication Details} \\ Sun, Q, Li, Z, Wang, M, Du, A \& Smith, SC (2012), Methane activation on Fe4 cluster: a density functional \\ theory study, Chemical Physics Letters, 550, pp. 41-46.
}




\title{
Methane Activation on $\mathrm{Fe}_{4}$ Cluster: A Density Functional Theory Study
}

\author{
Qiao Sun ${ }^{1 *}$, Zhen $\mathrm{Li}^{1,2}$, Meng Wang $^{3}$, Aijun $\mathrm{Du}^{1}$ and Sean C. Smith ${ }^{1,4}$ \\ ${ }^{1}$ Centre for Computational Molecular Science, Australian Institute for Bioengineering and \\ Nanotechnology, The University of Queensland, Qld 4072, Brisbane, Australia. \\ ${ }^{2}$ Institute of Superconducting \& Electronic Materials, The University of Wollongong, \\ NSW 2500, Australia. \\ ${ }^{3}$ Center for Bioengineering and Biotechnology, China University of Petroleum (East China), \\ Qingdao Economic \& Technical Development Zone, Qingdao 266555, China. \\ ${ }^{4}$ Center for Nanophase Materials Sciences, Oak Ridge National Laboratory, \\ Oak Ridge, TN 37831-6496
}

Corresponding author: Qiao Sun and Zhen Li

Email:

Tel : q.sun@uq.edu.au; zhenl@uow.edu.au

Fax : +61 733463949

+61 333463992 


\begin{abstract}
We report a comprehensive theoretical study on reaction of methane by $\mathrm{Fe}_{4}$ cluster. This study gain insight into the mechanism of the reaction and indicate the $\mathrm{Fe}_{4}$ cluster has strong catalytic effect on the activation reaction of methane. In detail, the results show the cleavage of the first $\mathrm{C}-\mathrm{H}$ bond is both an energetically and kinetically favourable process and the breaking of the second $\mathrm{C}-\mathrm{H}$ is the rate-determining step. Moreover, our study demonstrates that the different cluster size of iron can not only determine the catalytic activity of methane but also control the product selectivity.
\end{abstract}

Keywords Density functional theory; Methane; C-H cleavage; Fe cluster

\title{
1 Introduction
}

It is well known that finite clusters constitute a new state of matter with its own fascinating attributes.[1] Among all kinds of clusters, those consisting of transition metal (TM) elements are of particular interest due to their importance in heterogeneous catalysis on both their scientific and technological interests for industrial applications. Catalytic reactions of $\mathrm{CH}_{4}$ with nano TM clusters are of considerable importance in many industrial processes. Among TMs, iron, the heaviest element with a significant cosmic abundance, is a desirable catalyst for activating the $\mathrm{C}-\mathrm{H}$ bond in methane because it can decrease significantly the activation energy of $\mathrm{C}-\mathrm{H}$ bond [2, 3]. Recent research shows that iron can reduce the $\mathrm{C}-\mathrm{H}$ bond activation energy to about 8-20 $\mathrm{kcal} / \mathrm{mol}$, depending on the $\mathrm{Ni} / \mathrm{Fe}$ mixture [3]. Although small iron clusters are crucial in the catalytic reaction of activation of the $\mathrm{C}-\mathrm{H}$ bond, there are a few studies on methane activation by 
iron alone, and most of these have focused on bulk iron or iron cations [4-10]. With regards neutral Fe clusters, Yamamoto's group used Mössbauer spectroscopy to monitor the reaction between $\mathrm{Fe}_{2}$ and $\mathrm{CH}_{4}$ [11]. Castro studied the interaction of methane with $\mathrm{Fe}_{4}$ clusters and our group has investigated methane activation on Fe monomer and dimer by using density functional theory method $[12,13]$ The study of methane activation by neutral iron clusters which, beside its own importance, such as iron is one of the most economic affordable catalysts for methane activation reaction, may act as useful models for homogenous and heterogeneous catalysis.

The size dependence of reactivity of metal clusters has become a most fascinating and intriguing issue in modern cluster chemistry and has attracted much attention in both experimental and theoretical fields. It is well known the size of the active phase is one of the most important factors in determining the catalytic behaviour of a heterogeneous catalyst. For some TM clusters such as Pt clusters, the dimer through pentamer were found to be the most reactive, while larger clusters are much less reactive. For Pd clusters, $\mathrm{Pd}_{8}$ and $\mathrm{Pd}_{10}$ are the most reactive, while $\mathrm{Pd}_{3}$ and $\mathrm{Pd}_{9}$ activate $\mathrm{CH}_{4}$ more slowly [14]. Research shows that the catalytic properties of small iron clusters show large variations with cluster size [1]. From activation of methane by iron cluster cations, $\mathrm{Fe}_{\mathrm{n}}{ }^{+}(\mathrm{n}=2-15)$ : research find that there are barriers to the primary dehydrogenation reactions for all the clusters, except $n=3$ and 4 , on the basis of thermochemistry [5]. Previously we have simulated methane activation on Fe monomer and dimer [13], and our results indicate that the iron dimer $\mathrm{Fe}_{2}$ has a stronger catalytic effect on the activation of methane than the iron atom. Here we report methane activation by iron cluster $\mathrm{Fe}_{4}$ tetrahedron, while the activation reactions of methane on Fe bulk solid are actually in investigation. Through the comparison of the activation mechanisms of methane by different size of iron clusters, even atomic scale, cluster and bulk solid iron, the study will provide useful information to tune the relative reaction 
rates of the different steps during activation methane by controlling the catalytic iron size, which is very important for methane conversion from both scientific and industrial interests.

\section{Computational methods}

Density functional method of Perdew and Wang (i.e. BPW91) [15] method in conjunction with the $6-311+G^{*}$ basis set [16] were employed in the structural optimization for all reactants, products, intermediates and transition states involved in the reactions of $\mathrm{Fe}_{4}$ cluster with $\mathrm{CH}_{4}$. The selected method has been widely applied to electronic structure calculations on systems containing transition metals, and has been proven to combine reasonable computational cost with sufficient accuracy for transition metal systems $[17,18]$. Moreover, PW91 shows advantages in studying systems with periodic boundary conditions [19]. Frequency calculations at the same theoretical level were then performed to confirm whether the optimized species is a minimum or a saddle point.

AIM theory and NBO analysis which have been used to successfully determine intermolecular interactions of different systems were carried out on the basis of the optimized structures of $\mathrm{Fe}_{4}-$ $\mathrm{CH}_{4}$ system in order to better clarify the nature of the intermolecular interactions [18, 20-27]. In the AIM analyses, the existence of a bond is indicated by the presence of a so-called bond critical point (BCP). The strength of the bond can be estimated from the magnitude of the electron density $\left(\rho_{\mathrm{bcp}}\right)$ at the BCP. Similarly, the ring or cage structures are characterized by the existence of a ring critical point (RCP) or cage critical point (CCP). RCP is saddle point inside ring, whose Hessian matrix presents two positive eigenvalues and it is characteristic of cyclic structures. As the name suggests, CCP is the point where the surrounding of electron density meet each other and is surrounded by ring critical points. Furthermore, the nature of the interatomic interaction 
can be predicted from the topological parameters at the BCP, such as the Laplacian of electron density $\left(\nabla^{2} \rho_{\mathrm{bcp}}\right)$ and energy density $\left(H_{\mathrm{bcp}}\right)$. Generally, the sign of $\nabla^{2} \rho_{\mathrm{bcp}}$ reveals whether charge is concentrated $\left(\nabla^{2} \rho_{\mathrm{bcp}}<0\right)$ as in covalent bonds (shared interaction) or depleted $\left(\nabla^{2} \rho_{\mathrm{bcp}}>0\right)$ as in ionic bonds, H-bonds, and van der Waals interactions (closed-shell interaction). It is also reported that if $\nabla^{2} \rho_{\mathrm{bcp}}>0$ and $H_{\mathrm{bcp}}<0$, then the interaction is only partly covalent in nature [13]. Additionally, natural bond orbital (NBO) analysis was carried out to examine the interactions, such as H-bonding and van der Waals force of the systems. The topological analysis of the system was carried out via the AIMALL program [28].

To characterize the absorption strengths for methane on the $\mathrm{Fe}_{4}$ cluster, the binding energy $\Delta E$ has been introduced, which is defined as the energy difference between the formed $\mathrm{Fe}_{4}-\mathrm{CH}_{4}$ complex and the corresponding monomers. Moreover, zero-point vibrational energy (ZPVE) corrections and basis set superposition errors (BSSEs) calculations have also been considered, where the Boys-Bernardi counterpoise technique has been employed to evaluate the BSSEs [29]. In order to confirm transition structures for some key reaction steps, intrinsic reaction coordinate (IRC) calculations [30-31] have been performed to follow the reaction pathways. The calculations presented herein have been carried out using the Gaussian 03 suite of programs [32].

\section{Results and Discussions}

\subsection{Structural and energetic properties of $\mathrm{Fe}_{4}$ and $\mathrm{Fe}_{4}-\mathrm{CH}_{4}$}

To the best of our knowledge, we report here the first theoretical investigation on the methane dehydrogenation pathway on Fe tetramer. Our goal is to study whether the low-energy magnetic states of $\mathrm{Fe}_{4}$ cluster is able to activate the $\mathrm{C}-\mathrm{H}$ bonds of $\mathrm{CH}_{4}$. Figure 1 lists the optimized geometries of the various intermediates and transition states for the $\mathrm{Fe}_{4}-\mathrm{CH}_{4}$ system on the 
BPW91/6-311+G* level. We start the discussion from the reactants of the reaction. For $\mathrm{CH}_{4}$, in the ground state (GS), the $\mathrm{C}-\mathrm{H}$ bond lengths are $1.097 \AA$, with $\mathrm{H}-\mathrm{C}-\mathrm{H}$ angle of $109.5^{\circ}$. The GS of $\mathrm{Fe}_{4}$ cluster is a distorted tetrahedron, with a multiplicity $M=2 S+1=15$, where $S$ is the total spin. The magnetic moment of each Fe atom is $3.5 \mu_{\mathrm{B}}$ with an average bond length of $2.352 \AA$. Using the DFT method, Gutsev and Bauchlicher [33] as well as Berski et al [34] also found a distorted tetrahedron for the GS of $\mathrm{Fe}_{4}$, with $3.5 \mu_{\mathrm{B}}$ at each atomic site and with similar bond lengths as those in the present study.

The total, relative energies, BSSE and ZPE corrections of reactants, intermediates, transition states and products are summarized in the supporting information (Table S1). We can see from Table S1 that $\mathrm{Fe}_{4}$ cluster with $M=13$ state is located $2.2 \mathrm{kcal} / \mathrm{mol}$ above the GS; it has a shorter average bond length of $2.296 \AA$. Calculational results [12] indicate that the $M=17$, and $M=11$ states were found 8 and $14 \mathrm{kcal} / \mathrm{mol}$ above the GS, respectively. Gutsev and Bauchlicher [33] as well as Berski’s study also show the same order for the excited states [34]. So, in this paper, we only consider the activation reactions of methane by $\mathrm{Fe}_{4}$ cluster on its $\mathrm{GS}(M=15)$ and its first excited state $(M=13)$.

The intermediates and transition states along the potential energy surfaces of GS $(M=15)$ are labelled as $C_{n}(n=1,2,3,4)$ and $T_{n}(n=1,2,3)$ and those of the first excited state $(M=13)$ are labelled as $\mathrm{C}_{\mathrm{n}}{ }^{\prime}(\mathrm{n}=1,2,3,4)$ and $\mathrm{TS}_{\mathrm{n}}{ }^{\prime}(\mathrm{n}=1,2,3)$. The $\mathrm{C} 1$, GS of $\mathrm{Fe}_{4}-\mathrm{CH}_{4}$ complex, which was formed by the carbon atom of methane coordinated with a $\mathrm{Fe}$ atom of $\mathrm{Fe}_{4}$, with bond length, $\mathrm{Fe}-$ C, of $2.442 \AA$. An adduct $\mathrm{C}^{\prime}, \mathrm{Fe}_{4}-\mathrm{CH}_{4}$ with $M=13$ state, is also formed by $\mathrm{Fe}-\mathrm{C}$ interaction with the value of $2.597 \AA$. Subtracting the GS energies of $\mathrm{Fe}_{4}$ and $\mathrm{CH}_{4}$ from that of the $\mathrm{C} 1$, a binding energy, including the corrections of ZPE and BSSE of $2.0 \mathrm{kcal} / \mathrm{mol}$ is obtained, confirming a weak type interaction. With respect to $\mathrm{Fe}_{4}(M=15)$ of $\mathrm{GS}, \mathrm{C} 1$ ' is above 
$0.4 \mathrm{kcal} / \mathrm{mol}$ of the reactant asymptote $(M=15)$. But with respect to $\mathrm{Fe}_{4}$ of $M=13$, its binding energy is $1.8 \mathrm{kcal} / \mathrm{mol}$. From the bonding lengths and the binding energies we can draw a conclusion that the interaction between $\mathrm{Fe}_{4}$ and $\mathrm{CH}_{4}$ in $\mathrm{C} 1$ is stronger than that of $\mathrm{C} 1$ ', which is also supported AIM, mulliken atomic charges and NBO analysis.

As displayed in Figure 2, the interaction between $\mathrm{Fe}_{4}$ and $\mathrm{CH}_{4}$ can be confirmed by the existence of the bond critical point (BCP) of the Fe-C contact. The corresponding topological parameters at the BCP have been presented in Table 1 . As mentioned above, the electron density $\rho_{\text {bcp }}$ can be used to characterize the relative strength of the $\mathrm{Fe}-\mathrm{C}$ contact, and we can see that the interaction between $\mathrm{Fe}_{4}$ and $\mathrm{CH}_{4}$ in $\mathrm{C} 1$ is stronger than that of $\mathrm{C} 1$ ', which is also consistent with the $\mathrm{Fe}-\mathrm{C}$ contact distances shown in Figure 1. For the calculated Laplacians and energy densities at the BCPs, both of them are positive and negative, respectively. Therefore, the interactions between Fe and $\mathrm{C}$ atom are predominated by the electrostatic interactions as well as partial covalent characters in nature. Moreover, the $\mathrm{C} 1$ has more negative $H_{\mathrm{bcp}}$ than $\mathrm{C} 1$ ', implying that the strength of the Fe-C interaction of $\mathrm{C} 1$ is larger than that of $\mathrm{C} 1$ '. Mulliken atomic charges show that there is small transference of electrons (0.19e in $\mathrm{C} 1$ and $0.18 \mathrm{e}$ in $\mathrm{C} 1$ ') from $\mathrm{CH}_{4}$ to $\mathrm{Fe}_{4}$ through the C-Fe bond. This charge does not lie on the Fe atom, whereas it is stabilized on the other three Fe atoms which are far from $\mathrm{CH}_{4}$ moiety. The Fe atom and $\mathrm{H}$ atoms have positive charge of $0.050 \mathrm{e}$ and $0.308 \mathrm{e}$ in $\mathrm{C} 1$ and $0.039 \mathrm{e}$ and $0.307 \mathrm{e}$ in $\mathrm{C} 1$ ', and the carbon atom has negative charge of -1.087e in C1 and -1.072 in C1', which can interpret that interaction between $\mathrm{Fe}_{4}$ and $\mathrm{CH}_{4}$ in $\mathrm{C} 1(M=15)$ is stronger than that of $\mathrm{C}^{\prime}(M=13)$. NBO analysis shows that the second-order interaction energies from the two donor orbits $(\sigma(\mathrm{C}-\mathrm{H})$ to the acceptor orbits $(\mathrm{n} * \mathrm{Fe})$ are 6.3 and $4.6 \mathrm{kcal} / \mathrm{mol}$ of $\mathrm{C} 1$ and $\mathrm{C} 1$ ', respectively, which is in agreement with the results of the binding energy, AIM and mulliken atomic charges analysis. The energies of singly occupied 
molecular orbital (SOMO) orbital of the frontier orbits and the gap between HOMO and LUMO of some species of the system are shown in supporting information Table S2. The HOMOLUMO gap in bare methane is $9.67 \mathrm{eV}$. But in the GS of $\mathrm{Fe}_{4}-\mathrm{CH}_{4}(\mathrm{C} 1)$, the gap becomes smaller with a value only $0.90 \mathrm{eV}$, which means that the interaction with $\mathrm{Fe}_{4}$ activates the methane moiety. The gap of $M=13$ state is even smaller with a values only $0.21 \mathrm{eV}$. Normally, the higher HOMO energy is, the lower the LUMO energy is, and the narrower the LUMO-HOMO energygap is, the more chemically active the molecule is. We can see that C1' is more active than C1. In all, their weak interactions between $\mathrm{Fe}_{4}$ and $\mathrm{CH}_{4}$ of the two $\mathrm{Fe}_{4}-\mathrm{CH}_{4}$ complexes activate the methane moiety, and their interactions are the precondition of the activation reaction of methane on $\mathrm{Fe}_{4}$ cluster. For the following discussions, we will focus on the activation reaction of methane by $\mathrm{Fe}_{4}$ cluster on these two states.

\subsection{Dehydrogenation of $\mathrm{CH}_{4}$ on $\mathrm{Fe}_{4}$}

For the activation reactions of methane on TM tetramers, previously experimental and theoretical results indicated the most energetically favourable products are (TM) $)_{4} \mathrm{CH}_{2}$ and $\mathrm{H}_{2}$ [17]. So in this paper, we mainly focus on the reaction pathways with production of $\mathrm{Fe}_{4} \mathrm{CH}_{2}$ and $\mathrm{H}_{2}$. We have plotted in Figure 3 the $\mathrm{CH}_{4}$ dehydrogenation pathways in the presence of $M=13$ and $M=15$ states of $\mathrm{Fe}_{4}$. The first vibrational frequencies of the reactants, intermediates, transition states and products of these two states have been listed in Table 2. The number of imaginary frequencies can confirm whether there is a local minimum or a transition state.

For the activation reaction of methane on the catalyst $\mathrm{Fe}_{4}$, firstly, two $\mathrm{Fe}_{4}-\mathrm{CH}_{4}$ adducts $\mathrm{C} 1$ and C1' are formed, which are $-2.0 \mathrm{kcal} / \mathrm{mol}(\mathrm{C} 1)$ and $0.4 \mathrm{kcal} / \mathrm{mol}(\mathrm{C} 1$ ') relative to the reactant asymptote $(M=15)$. The weak interactions between $\mathrm{Fe}_{4}$ and $\mathrm{CH}_{4}$ of the two $\mathrm{Fe}_{4}-\mathrm{CH}_{4}$ complexes activate the methane moiety, which are the precondition of the activation reaction of methane on 
$\mathrm{Fe}_{4}$ cluster. In TS1 and TS1', the bond lengths of $\mathrm{C}-\mathrm{H} 1$ are $1.599 \AA$ and $1.548 \AA$ respectively,

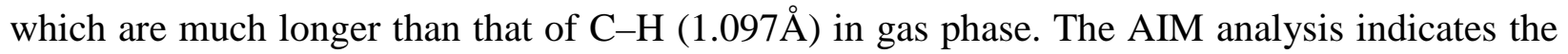
formation of a $\mathrm{Fe}-\mathrm{H} 1$ by the presence of the so-called bond critical point (BCP) and a three atoms ring, $\mathrm{Fe}-\mathrm{C}-\mathrm{H} 1$, is characterized by the existence of a ring critical point (RCP). The imaginary frequencies of TS1 $\left(892 \mathrm{i} \mathrm{cm}^{-1}\right)$ and TS1' $\left(951 \mathrm{i} \mathrm{cm}{ }^{-1}\right)$ are assigned to the stretch mode of $\mathrm{C}-\mathrm{H}$ for the breaking of the bond. From Figure 3 we can see that the first $\mathrm{C}-\mathrm{H}$ bond of $\mathrm{C} 1$ and C1' will be broken if about $12.4 \mathrm{kcal} / \mathrm{mol}$ (via TS1) and $8.2 \mathrm{kcal} / \mathrm{mol}$ (via TS1') are provided, and consequently two stable intermediates $\left(\mathrm{H}-\mathrm{Fe}_{4}-\mathrm{CH}_{3}\right), \mathrm{C} 2$ and $\mathrm{C} 2$ ', will be formed, which is 15.8 $\mathrm{kcal} / \mathrm{mol}$ (C2) and $17.0 \mathrm{kcal} / \mathrm{mol}$ (C2') below the reactant asymptote. We can see that the intermediate $\mathrm{CH}_{3} \mathrm{Fe}_{4} \mathrm{H}$ is much more stable than those of the corresponding intermediates $\mathrm{CH}_{3} \mathrm{FeH}$ and $\mathrm{CH}_{3} \mathrm{Fe}_{2} \mathrm{H}$ with the methane reaction of $\mathrm{Fe}$ atom and Fe dimmer at the BPW91 level [13]. Our results show that the breaking of the first $\mathrm{C}-\mathrm{H}$ bond of methane in the presence of $\mathrm{Fe}_{4}$ is both an energetically and kinetically favorable process. Moreover, from the potential energy surfaces we can see that the first $\mathrm{C}-\mathrm{H}$ activation takes place most likely through a crossover between $M=13$ and $M=15$ potential surfaces.

As shown in Figure 3, to break the second $\mathrm{C}-\mathrm{H}$ bond, the intermediate $\mathrm{CH}_{3} \mathrm{Fe}_{4} \mathrm{H}, \mathrm{C} 2$ and $\mathrm{C} 2$ have to overcome a transition state with the energy barrier of $27.3 \mathrm{kcal} / \mathrm{mol}$ (TS2) and 25.4 $\mathrm{kcal} / \mathrm{mol}$ (TS2') on $M=15$ and $M=13$ states, respectively. The AIM analysis (Figure 2) indicates the formation $\mathrm{Fe}-\mathrm{H} 2$ by the presence of $\mathrm{BCP}$. The bond lengths of the second $\mathrm{C}-\mathrm{H} 2$ are $1.881 \AA$ and $1.740 \AA$ in TS2 and TS2', respectively, and the imaginary frequencies of TS2 $\left(645 \mathrm{i} \mathrm{cm}^{-1}\right)$ and TS2 $\left(685 \mathrm{i} \mathrm{cm}^{-1}\right)$ are assigned to the stretch mode of $\mathrm{C}-\mathrm{H}$ bond, which indicate the breaking the second $\mathrm{C}-\mathrm{H}$ bond, followed by an intermediate $\mathrm{CH}_{2} \mathrm{Fe}_{4} \mathrm{HH}$ (C3 and C3') with $10.0 \mathrm{kcal} / \mathrm{mol}$ and $8.1 \mathrm{kcal} / \mathrm{mol}$ below the reactant asymptote of the two states. The gaps of C3 
$(1.63 \mathrm{eV})$ and $\mathrm{C}^{\prime}(0.70 \mathrm{eV})$ show C3' is more active than C3. We can see that the intermediate $\mathrm{CH}_{2} \mathrm{Fe}_{4} \mathrm{HH}$ is much more stable than those of the corresponding intermediate $\mathrm{CH}_{2} \mathrm{FeHH}$ and $\mathrm{CH}_{2} \mathrm{Fe}_{2} \mathrm{HH}$ in reaction of methane on Fe atom and Fe dimmer at the BPW91 level [13]. The calculations also show the cleavage of the second $\mathrm{C}-\mathrm{H}$ bond on $\mathrm{Fe}_{4}$ is more difficult than that of the first $\mathrm{C}-\mathrm{H}$ bond.

The next step in the dehydrogenation is the formation of a complex $\mathrm{H}_{2} \mathrm{FeCH}_{2}$, in which the hydrogen molecules bond weakly to the $\mathrm{Fe}-\mathrm{CH}_{2}$. For the transition states of dehydrogenation via TS3 and TS3', the AIM analysis shows the formation of a H1-H2 by the presence of the BCP and a three atoms ring, $\mathrm{H} 1-\mathrm{Fe}-\mathrm{H} 2$, RCP. The imaginary frequencies of TS3 $\left(832 \mathrm{i} \mathrm{cm}^{-1}\right)$ and TS3' (773i $\mathrm{cm}^{-1}$ ) are assigned to the stretch mode of $\mathrm{H}-\mathrm{H}$ bond for the forming $\mathrm{H}_{2}$. As the following product $\mathrm{C} 4$ and $\mathrm{C} 4$ ', the disappearing RCP illuminates the breaking of the three atom ring, $\mathrm{H} 1-\mathrm{Fe}-\mathrm{H} 2$, and disappearing $\mathrm{BCP}$ shows the breaking one of $\mathrm{Fe}-\mathrm{H}$ comparing with the AIM analysis of TS3 and TS3'. The distance between the Fe and the two $\mathrm{H}$ atoms in the $\mathrm{H}_{2}$ unit is about $1.8 \AA$ in $\mathrm{C} 4$ and $1.7 \AA$ in $\mathrm{C} 4$ ', which is much longer than the calculated $\mathrm{Fe}-\mathrm{H}$ value of $1.553 \AA$ in gas-phase due to the $\mathrm{Fe}-\mathrm{H}$ interactions. The bond distance between the two hydrogen atoms in the $\mathrm{H}_{2}$ unit is $0.822 \AA$ in $\mathrm{C} 4$ and $0.877 \AA$ in $\mathrm{C} 4$ ', which is slightly longer than the $\mathrm{H}-\mathrm{H}$ bond of $\mathrm{H}_{2}$ in the gas phase, that is, $0.748 \AA$. Moreover, the $\mathrm{Fe}-\mathrm{C}$ bonds around $2.0 \AA$ in $\mathrm{C} 4$ and around $1.9 \AA$ in C4' is also larger than the gas-phase value of $1.686 \AA$ due to the interaction of Fe atom with the $\mathrm{H}_{2}$ unit. The energy barriers $27.4 \mathrm{kcal} / \mathrm{mol}$ for $M=15$ state and $16.6 \mathrm{kcal} / \mathrm{mol}$ for $M=13$ state, have to be overcome to form the $\mathrm{H}_{2} \mathrm{FeCH}_{2}$ complex through the transition states (TS3 and TS3'), which are $17.4 \mathrm{kcal} / \mathrm{mol}$ and $8.5 \mathrm{kcal} / \mathrm{mol}$ above the reactant asymptote. Once the intermediate $\mathrm{H}_{2} \mathrm{Fe}_{4} \mathrm{CH}_{2}$ is formed, the following steps involve the migration of $\mathrm{H}$ atom, combination of $\mathrm{H}$ atoms to form $\mathrm{H}_{2}$, and finally dissociation of $\mathrm{H}_{2}$. As the dehydrogenation 
products, $\mathrm{Fe}_{4} \mathrm{CH}_{2}+\mathrm{H}_{2}$, are $15.3 \mathrm{kcal} / \mathrm{mol}$ and $9.2 \mathrm{kcal} / \mathrm{mol}$ above the reactant asymptote of $M=$ 15 and $M=13$, respectively, which means that methane dehydrogenation in the presence of $\mathrm{Fe}_{4}$ cluster is endothermic.

From Figure 3 and discussed above we can see that among the three single steps, on $M=13$ state, the one involving the breaking of the second $\mathrm{C}-\mathrm{H}$ bond is the rate-limiting step. While for $M=$ 15 state, the cleavage of the second $\mathrm{C}-\mathrm{H}$ bond and $\mathrm{H}_{2}$ elimination from the dihydrogen complex are difficult comparing with the cleavage of the first $\mathrm{C}-\mathrm{H}$ bond. Here we will compare the activation reactions of methane on iron atom and dimer. For the methane activation on iron atom, our previous publication [13] suggests that the first $\mathrm{C}-\mathrm{H}$ activation takes place most likely through a crossover between the triplet and quintet potential surfaces and the cleavage of the second $\mathrm{C}-\mathrm{H}$ bond is neither an energetically and kinetically favourable process. Our study also explains the experimental observation $\mathrm{HFeCH}_{3}$ complex rather than $\mathrm{CH}_{2} \mathrm{FeH}_{2}$ complex of by $\mathrm{Fe}-$ $\mathrm{CH}_{4}$ system, while for $\mathrm{Fe}_{4}-\mathrm{CH}_{4}$ system, the products $\mathrm{CH}_{3} \mathrm{Fe}_{4} \mathrm{H}$ and $\mathrm{CH}_{2} \mathrm{Fe}_{4} \mathrm{HH}$ of can be obtained based on our calculations. For activation reactions of methane on Fe dimer, the cleavage of the first and second $\mathrm{C}-\mathrm{H}$ bond are both facile, and $\mathrm{H}_{2}$ eliminated from the dihydrogen complex is the rate-determining step, while for active reaction of methane by $\mathrm{Fe}_{4}$ cluster, the first $\mathrm{C}-\mathrm{H}$ bond cleavage is facile and the second $\mathrm{C}-\mathrm{H}$ breaking is more difficult than that of by Fe dimer. We can see that the cluster size of iron can not only determine the catalytic activity of methane but also control their product selectivity. Furthermore, the activation reactions of methane on bulk solid are actually in investigation. The present studies serve as the probes for the activation mechanism of methane on small Fe clusters, providing an interesting contrast to the bulk solid. 


\section{Conclusions}

Density functional theory (DFT) calculations have been carried out to explore the activation reactions of methane catalysed $\mathrm{Fe}_{4}$ cluster with different spin states. Various intermediates, transition states, and products in the activation reaction are fully optimized at the BPW91/6$311+G^{*}$ level. The potential energy surfaces (PES) corresponding to $\mathrm{Fe}_{4}$ cluster with two states of $M=13$ and $M=15$ (the total multiplicity: $M=2 \mathrm{~S}+1, \mathrm{~S}=$ total spin states) are examined in detail. Our calculational results show the barrier of the cleavage of the first C-H bond is only 8.2 $\mathrm{kcal} / \mathrm{mol}$ on $M=13$ state, and $12.4 \mathrm{kcal} / \mathrm{mol}$ on $M=15$ state, which is both an energetically and kinetically favourable process. The results also suggest that the first $\mathrm{C}-\mathrm{H}$ activation takes place most likely through a crossover between $M=13$ and $M=15$ potential surfaces. The cleavage of the second $\mathrm{C}-\mathrm{H}$ bond is relatively difficult compared with that of the first one, and the barrier is 25.4 and $27.2 \mathrm{kcal} / \mathrm{mol}$ on $M=13$ and $M=15$ states, respectively. For $\mathrm{H}_{2}$ elimination, the process on the PES of $M=13$ state is feasible, with the activation barrier of $16.6 \mathrm{kcal} / \mathrm{mol}$. Our calculational results show the cleavage of the first $\mathrm{C}-\mathrm{H}$ bond is quite facile than that of the second $\mathrm{C}-\mathrm{H}$ bond. The breaking the second $\mathrm{C}-\mathrm{H}$ bond is the rate-limiting step. The relative energies of the intermediates $\mathrm{C} 2$ and $\mathrm{C}^{\prime}{ }^{\prime}$ are -15.8 and $-17.0 \mathrm{kcal} / \mathrm{mol}$ and $\mathrm{C} 3$ and $\mathrm{C}^{\prime}{ }^{\prime}$ are -8.1 and $-10.3 \mathrm{kcal} / \mathrm{mol}$, on $M=15$ and $M=13$ states, respectively. So we can predict that the products $\mathrm{CH}_{3} \mathrm{Fe}_{4} \mathrm{H}$ and $\mathrm{CH}_{2} \mathrm{Fe}_{4} \mathrm{HH}$ can be obtained. In all, the study on one hand gains insight into that the strong catalytic effect of $\mathrm{Fe}_{4}$ cluster in the activation reaction of methane, on the other hand, demonstrates that the size of iron cluster can not only determine the activity of methane activation but also control the product selectivity. With the aid of knowledge of reaction mechanism, the size effect can provide deep insights into for the conversion of reactants and for 
the formation of different products. These insights will undoubtedly be helpful for the rational design of highly efficient catalysts.

\section{Acknowledgement}

We are grateful to the Australian Research Council and The University of Queensland for supporting this work. We also acknowledge generous grants of high performance computer time from both The University of Queensland and the National Computational Infrastructure (NCI). Dr. Qiao Sun and Dr Zhen Li gratefully acknowledge respective support from a University of Queensland Postdoctoral Fellowship and a Queensland Smart Future Fellowship. 


\section{Captions}

Figure 1 Optimized structures of transition states and intermediates of $\mathrm{Fe}_{4}$ cluster activation reaction of methane of $M=15$ and $M=13$ states based on the BPW91/6-311+G* level (bond lengths in angstroms and bond angles in degrees, and the parameters in brackets are from the system with $M=13$ state).

Figure 2 The molecular graphs of the intermediates and transition state of $\mathrm{Fe}_{4}$ cluster activation reaction of methane, where the bond critical points (BCPs), ring critical points (RCPs) and cage critical point (CCP) are denoted as small green, red and blue dots, respectively.

Figure 3 Potential energy profiles of dehydrogenation and $\mathrm{H}$ elimination reactions of $\mathrm{CH}_{4}$ and $\mathrm{Fe}_{4}$ of $M=15$ and $M=13$ states based on the BPW91/6-311+G* level.

Table 1 The calculated topological parameters at the BCPs of the $\mathrm{Fe}_{4}-\mathrm{CH}_{4}$ system.

Table 2 Calculated first vibrational frequencies $\left(\mathrm{cm}^{-1}\right)$ and the vibrational mode assignments of $\mathrm{Fe}_{4}-\mathrm{CH}_{4}$ system of $M=15$ and $M=13$ states at the BPW91/6-311+G* level. 


\section{References}

[1] J. Bansmann, S.H. Baker, C. Binns, J.A. Blackman, J.P. Bucher, J. Dorantes-Davila, V. Dupuis, L. Favre, D. Kechrakos, A. Kleibert, K.H. Meiwes-Broer, G.M. Pastor, A. Perez, O. Toulemonde, K.N. Trohidou, J. Tuaillon, Y. Xie, Surf. Sci. Rep. 56 (2005) 189-275.

[2] P. Schnabel, M.P. Irion, K.G. Weil, J. Phys. Chem. 95 (1991) 9688-9694.

[3] H. Yang, J.L. Whitten, Surf. Sci. 289 (1993) 30-38.

[4] A.B. Anderson, J.J. Maloney, J. Phys. Chem. 92 (1988) 809-812.

[5] R. Liyanage, X.G. Zhang, P.B. Armentrout, J. Chem. Phys. 115 (2001) 9747-9763.

[6] G.A. Ozin, J.G. McCaffrey, J. Am. Chem. Soc. 104 (1982) 7351-7352.

[7] S. Chiodo, I. Rivalta, M.D. Michelini, N. Russo, E. Sicilia, J.M. Ugalde, J. Phys. Chem. A. 110 (2006) 12501-12511.

[8] G.A. Ozin, J.G. McCaffrey, Inorg. Chem. 22 (1983) 1397-1399.

[9] G.A. Ozin, J.G. McCaffrey, D.F. McIntosh, Pure Appl. Chem. 56 (1984) 111-128.

[10] A.B. Anderson, J. Am. Chem. Soc. 99 (1977) 696-707.

[11] Y. Yamada, K. Katsumata, H. Shimasaki, Y. Ono, K. Yamaguchi, Bull. Chem. Soc. Jpn. 75 (2002) 277-281.

[12] M. Castro, Chem. Phys. Lett. 446 (2007) 333-338.

[13] Q. Sun, Li. Z, A.J. Du, J.-L. Chen, Z-H. Zhu, S.C. Smith, Fuel, 96 (2012) 291-297

[14] D.J. Trevor, D.M. Cox, A. Kaldor, J. Am. Chem. Soc. 112 (1990) 3742-3749.

[15] J.P. Perdew, Y. Wang, Phys. Rev. B. 45 (1992) 13244-13249.

[16] M.J. Frisch, J.A. Pople, J.S. Binkley, J. Chem. Phys. 80 (1984) 3265-3269.

[17] L. Xiao, L.C. Wang, J. Phys. Chem. B. 111 (2007) 1657-1663.

[18] Q. Sun, M.N. Altarawneh, B.Z. Dlugogorski, E.M. Kennedy, J.C. Mackie, Environ. Sci. Technol. 41 (2007) 5708-5715.

[19] L.V. Moskaleva, Z.X. Chen, H.A. Aleksandrov, A.B. Mohammed, Q. Sun, N. Rosch, J. Phys. Chem. C. 113 (2009) 2512-2520.

[20] Q. Sun, J.C. Mackie, B.Z. Dlugogorski, E.M. Kennedy, Chem. Phys. Lett. 436 (2007) 6874.

[21] Q. Sun, Z. Li, X.Q. Zeng, M.F. Ge, D.X. Wang, Chin. J. Chem. 23 (2005) 483-490.

[22] Q. Sun, Z. Li, X.Q. Zeng, M.F. Ge, D.X. Wang, J. Mol. Struct. (Theochem). 724 (2005) 167-172.

[23] Q. Sun, Z. Li, X.Q. Zeng, M.F. Ge, D.X. Wang, J. Mol. Struct. (Theochem). 724 (2005) 155-161.

[24] A.E. Reed, L.A. Curtiss, F. Weinhold, Chem. Rev. 88 (1988) 899-926. 
[25] P. Li, Y. Zhai, W. Wang, Z. Ma, S. Bi, H. Sun, Struct Chem. 22 (2011) 783-793.

[26] P. Li, Z.-Y. Ma, W.-H. Wang, Z.-T. Shen, S.-W. Bi, H.-T. Sun, Y.-X. Bu, ChemPhysChem. 11 (2010) 696-705.

[27] R.F.W. Bader, Atoms in Molecules: A Quantum Theory, Oxford University Press, New York, 1990.

[28] T.A. Keith, AIMAll (Version 11.12.19), TK Gristmill Software, Overland Park KS, USA, 2011 (aim.tkgristmill.com).

[29] S.F. Boys, F. Bernardi, Mol. Phys. 19 (1970) 553-566.

[30] K. Fukui, S. Kato, H. Fujimoto, J. Am. Chem. Soc, 97(1975) 1-7.

[31] C. Gonzalez, H.B. Schlegel, International Conf in Honor of Professor John a Pople : Forty Years of Quantum Chemistry, Athens, Ga, 1989, pp. 5523-5527.

[32] M.J.T. Frisch, G. W.; Schlegel, H. B.; Scuseria, G. E.; Robb, M. A.; Cheeseman, J. R.; Montgomery, Jr., J. A.; Vreven, T.; Kudin, K. N.; Burant, J. C.; Millam, J. M.; Iyengar, S. S.; Tomasi, J.; Barone, V.; Mennucci, B.; Cossi, M.; Scalmani, G.; Rega, N.; Petersson, G. A.; Nakatsuji, H.; Hada, M.; Ehara, M.; Toyota, K.; Fukuda, R.; Hasegawa, J.; Ishida, M.; Nakajima, T.; Honda, Y.; Kitao, O.; Nakai, H.; Klene, M.; Li, X.; Knox, J. E.; Hratchian, H. P.; Cross, J. B.; Bakken, V.; Adamo, C.; Jaramillo, J.; Gomperts, R.; Stratmann, R. E.; Yazyev, O.; Austin, A. J.; Cammi, R.; Pomelli, C.; Ochterski, J. W.; Ayala, P. Y.; Morokuma, K.; Voth, G. A.; Salvador, P.; Dannenberg, J. J.; Zakrzewski, V. G.; Dapprich, S.; Daniels, A. D.; Strain, M. C.; Farkas, O.; Malick, D. K.; Rabuck, A. D.; Raghavachari, K.; Foresman, J. B.; Ortiz, J. V.; Cui, Q.; Baboul, A. G.; Clifford, S.; Cioslowski, J.; Stefanov, B. B.; Liu, G.; Liashenko, A.; Piskorz, P.; Komaromi, I.; Martin, R. L.; Fox, D. J.; Keith, T.; Al-Laham, M. A.; Peng, C. Y.; Nanayakkara, A.; Challacombe, M.; Gill, P. M. W.; Johnson, B.; Chen, W.; Wong, M. W.; Gonzalez, C.; and Pople, J. A.; Gaussian, Inc., Wallingford CT, 2004., Gaussian 03, Revision C.02, ( 2004).

[33] G.L. Gutsev, C.W. Bauschlicher, J. Phys. Chem. A. 107 (2003) 7013-7023.

[34] S. Berski, G.L. Gutsev, M.D. Mochena, J. Andres, J. Phys. Chem. A. 108 (2004) 60256031. 


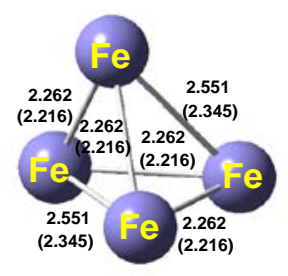

Fe4 (Fe4')

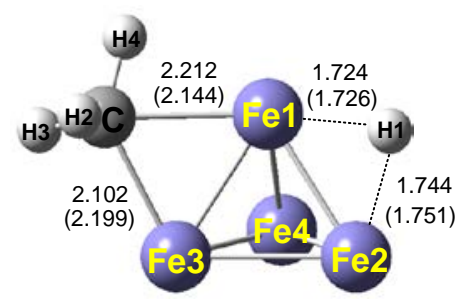

C2 (C2')

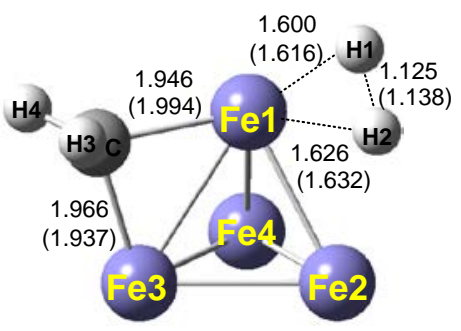

TS3 (TS3')
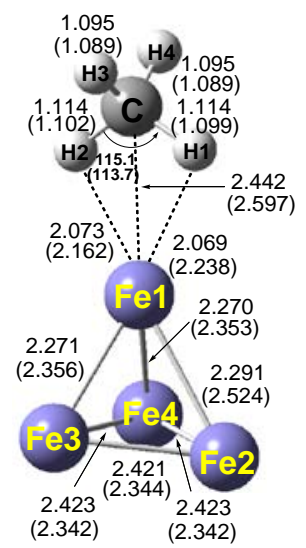

C1 (C1')

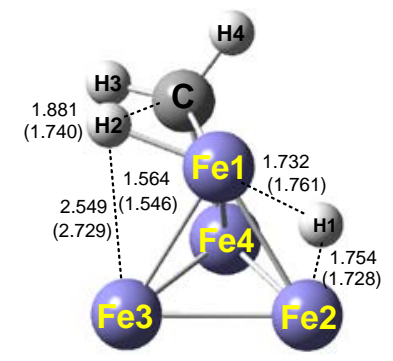

TS2 (TS2')

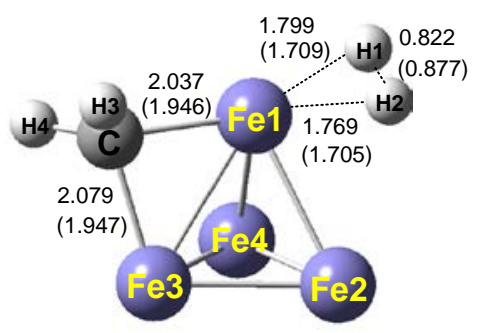

C4 (C4')

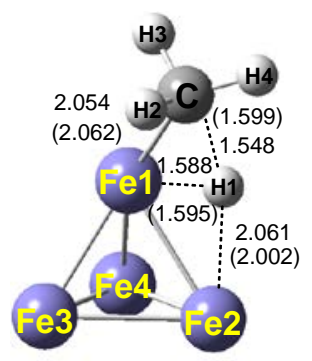

TS1 (TS1')

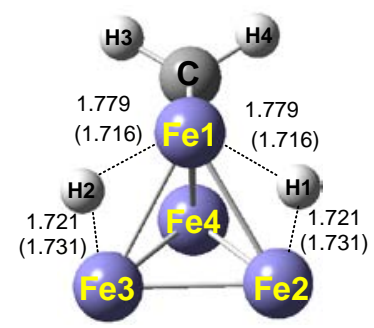

C3 (C3')

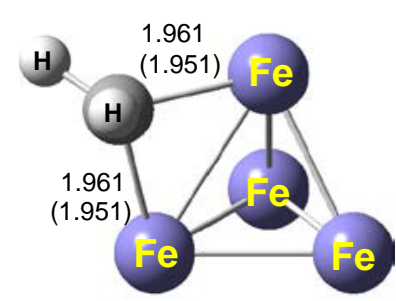

$\mathrm{CH}_{2}-\mathrm{Fe}_{4}\left(\mathrm{CH}_{2}-\mathrm{Fe}_{4}{ }^{\prime}\right)$

Figure 1 


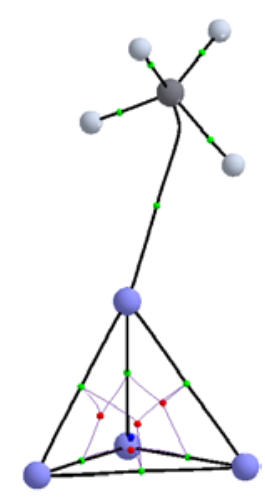

C1

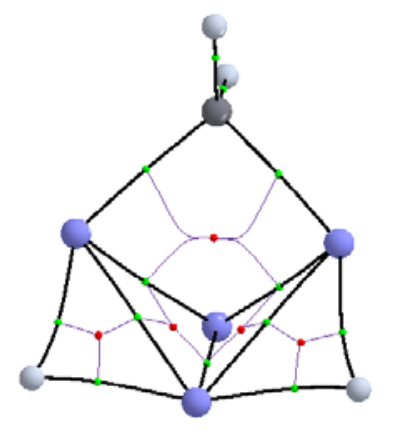

C3

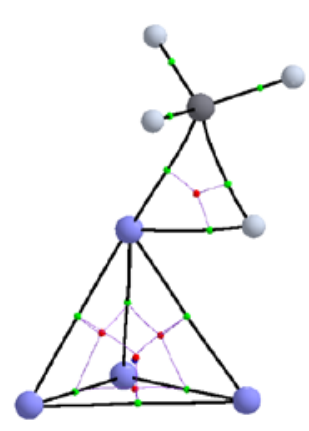

TS1

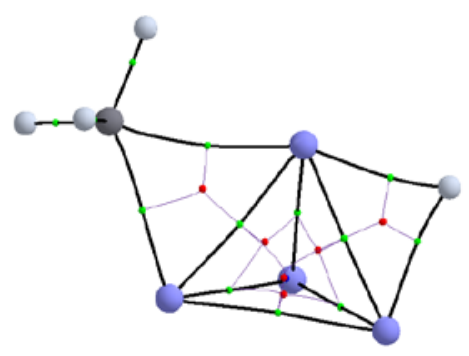

C2

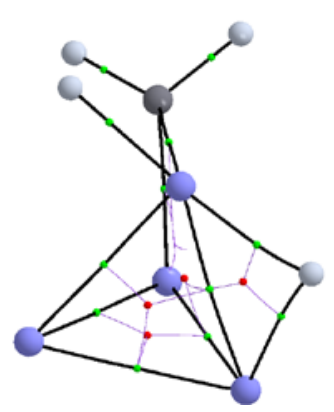

TS2

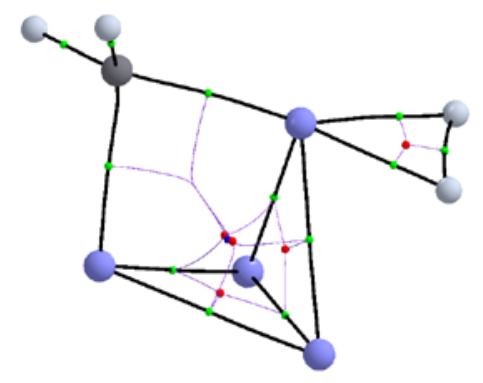

TS3

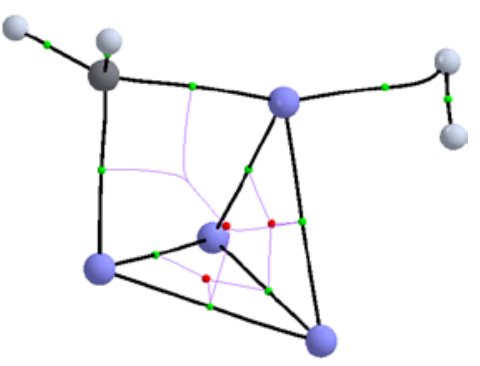

C4

Figure 2 


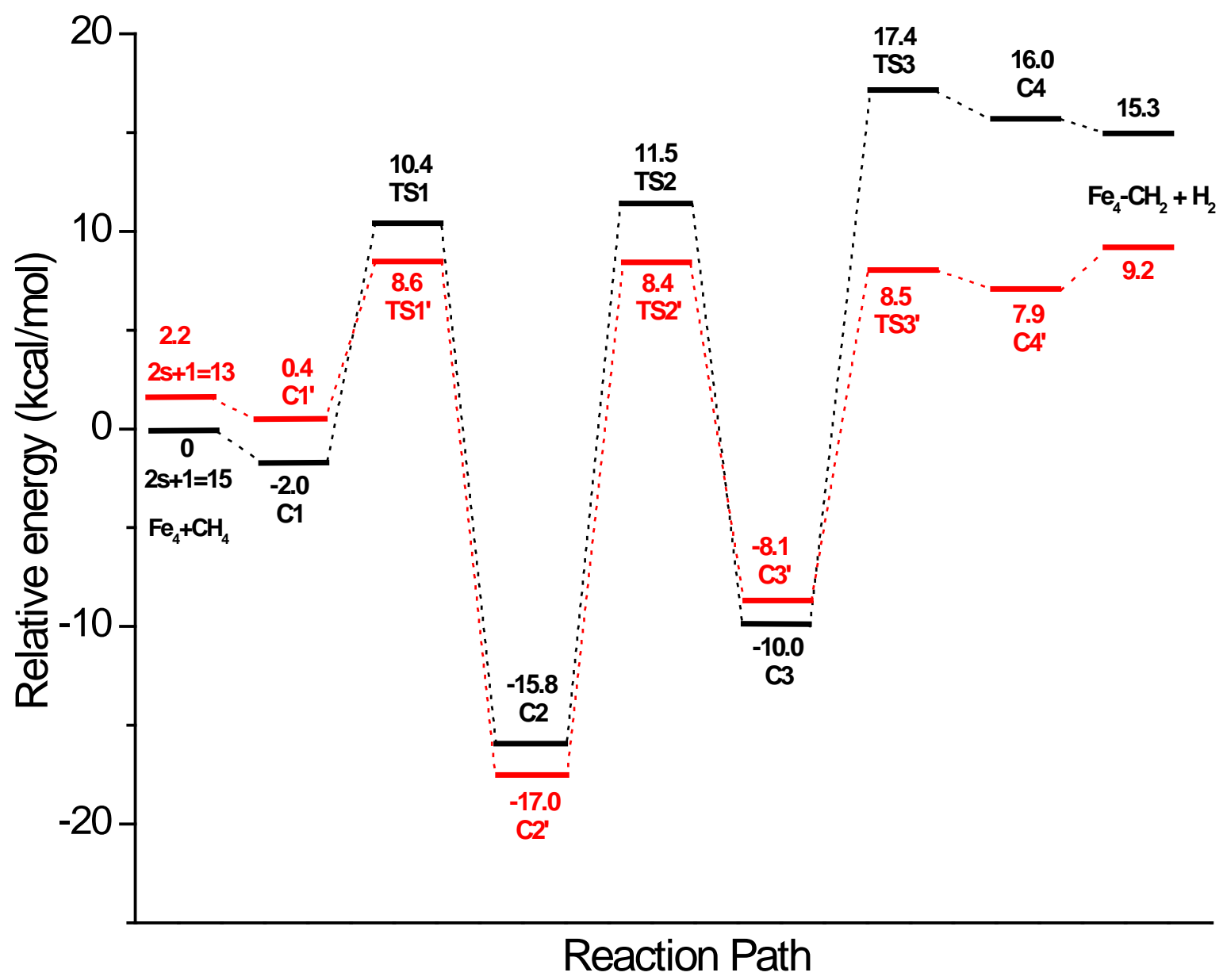

Figure 3 
Table 1 The calculated topological parameters at the BCPs of the $\mathrm{Fe}_{4}-\mathrm{CH}_{4}$ system.

\begin{tabular}{|c|c|c|c|c|c|c|}
\hline Complexes & $\mathrm{BCP}^{a}$ & $\rho_{\text {bcp }}$ & $\nabla^{2} \rho_{\text {bcp }}$ & $V_{\mathrm{bcp}}$ & $G_{\text {bcp }}$ & $H_{\mathrm{bcp}}$ \\
\hline C1 & Fe1-C & 0.0383 & 0.1398 & -0.0471 & 0.0384 & -0.0087 \\
\hline C1' & Fe1-C & 0.0370 & 0.1313 & -0.0398 & 0.0363 & -0.0035 \\
\hline \multirow[t]{3}{*}{ TS1 } & Fe1-C & 0.0918 & 0.1722 & -0.0969 & 0.0700 & -0.0269 \\
\hline & $\mathrm{C}-\cdot \mathrm{H} 1$ & 0.0910 & 0.0229 & -0.0666 & 0.0362 & -0.0304 \\
\hline & Fe1-H1 & 0.0973 & 0.1716 & -0.1132 & 0.0781 & -0.0351 \\
\hline \multirow[t]{3}{*}{ TS1' } & Fe1-C & 0.0927 & 0.1850 & -0.1005 & 0.0733 & -0.0272 \\
\hline & $\mathrm{C}-\mathrm{H} 1$ & 0.1005 & 0.0013 & -0.0765 & 0.0384 & -0.0381 \\
\hline & Fe1-H1 & 0.0985 & 0.1800 & -0.1174 & 0.0812 & -0.0362 \\
\hline \multirow[t]{4}{*}{ C2 } & Fe1-C & 0.0759 & 0.1706 & -0.0784 & 0.0605 & -0.0179 \\
\hline & $\mathrm{Fe} 3-\mathrm{C}$ & 0.0670 & 0.1564 & -0.0672 & 0.0532 & -0.0140 \\
\hline & Fe1-H1 & 0.0774 & 0.1685 & -0.0811 & 0.0616 & -0.0195 \\
\hline & Fe2-H1 & 0.0744 & 0.1618 & -0.0759 & 0.0582 & -0.0177 \\
\hline \multirow[t]{4}{*}{ C2' } & $\mathrm{Fe} 1-\mathrm{C}$ & 0.0650 & 0.1624 & -0.0674 & 0.0540 & -0.0134 \\
\hline & Fe3-C & 0.0833 & 0.1888 & -0.0891 & 0.0681 & -0.0210 \\
\hline & Fe1-H1 & 0.0791 & 0.1709 & -0.0840 & 0.0633 & -0.0207 \\
\hline & Fe2-H1 & 0.0754 & 0.1774 & -0.0808 & 0.0626 & -0.0182 \\
\hline TS2 & Fe1-H2 & 0.1105 & 0.1055 & -0.1200 & 0.0732 & -0.0468 \\
\hline TS2' & $\mathrm{Fe} 1-\mathrm{H} 2$ & 0.1228 & 0.1097 & -0.1225 & 0.0766 & -0.0459 \\
\hline \multirow[t]{2}{*}{ C3 } & Fe1-H2 & 0.0699 & 0.1624 & -0.0714 & 0.0560 & -0.0154 \\
\hline & Fe3-H2 & 0.0789 & 0.1629 & -0.0817 & 0.0612 & -0.0205 \\
\hline \multirow[t]{2}{*}{ C3' } & $\mathrm{Fe} 1-\mathrm{H} 2$ & 0.0787 & 0.1738 & -0.0844 & 0.0639 & -0.0205 \\
\hline & Fe3-H2 & 0.0715 & 0.1663 & -0.0743 & 0.0579 & -0.0164 \\
\hline \multirow[t]{3}{*}{ TS3 } & Fe1-H1 & 0.1002 & 0.1280 & -0.1082 & 0.0701 & -0.0381 \\
\hline & $\mathrm{Fe} 1-\mathrm{H} 2$ & 0.0929 & 0.1802 & -0.1081 & 0.0766 & -0.0315 \\
\hline & $\mathrm{H} 1-\mathrm{H} 2$ & 0.0873 & 0.0192 & -0.0643 & 0.0345 & -0.0298 \\
\hline \multirow[t]{3}{*}{ TS3' } & Fe1-H1 & 0.1017 & 0.1541 & -0.1156 & 0.0771 & -0.0385 \\
\hline & Fe1-H2 & 0.0938 & 0.2074 & -0.1150 & 0.0834 & -0.0316 \\
\hline & $\mathrm{H} 1-\mathrm{H} 2$ & 0.1057 & -0.0492 & -0.0824 & 0.0351 & -0.0473 \\
\hline \multirow[t]{2}{*}{$\mathrm{C} 4$} & Fe1-H1 & 0.0659 & 0.2862 & -0.0849 & 0.0782 & -0.0067 \\
\hline & H1-H2 & 0.1997 & -0.5408 & -0.1649 & 0.0148 & -0.1501 \\
\hline \multirow[t]{2}{*}{ C4' } & Fe1-H1 & 0.0789 & 0.2823 & -0.0995 & 0.0852 & -0.0143 \\
\hline & $\mathrm{H} 1-\mathrm{H} 2$ & 0.1746 & -0.3860 & -0.1422 & 0.0228 & -0.1194 \\
\hline
\end{tabular}

${ }^{a}$ Atomic numbering refers to Figure 1 . The $\rho_{\text {bcp }}, \nabla^{2} \rho_{\text {bcp }}, V_{\text {bcp }}, G_{\text {bcp }}$, and $H_{\text {bcp }}$ is electron density, the Laplacian of the electron density, potential energy density, kinetic energy density, and energy density at the $\mathrm{BCP}$, respectively. 
Table 2 Calculated first vibrational frequencies $\left(\mathrm{cm}^{-1}\right)$ and the vibrational mode assignments of $\mathrm{Fe}_{4}-\mathrm{CH}_{4}$ system of $M=15$ and $M=13$ states at the BPW91/6-311+G* level.

\begin{tabular}{|c|c|c|}
\hline species & Freq & Mode assignment \\
\hline $\mathrm{H}_{2}$ & 4312 & $\mathrm{H}-\mathrm{H}$ stretch \\
\hline $\mathrm{CH}_{4}$ & 1313 & Molecule bend \\
\hline \multicolumn{3}{|l|}{$M=15$} \\
\hline $\mathrm{Fe}_{4}$ & 105 & $\mathrm{Fe}-\mathrm{Fe}$ stretch \\
\hline $\mathrm{C} 1$ & 25 & Molecule rock out of plane \\
\hline TS1 & $892 \mathrm{i}$ & $\mathrm{C}-\mathrm{H}$ stretch \\
\hline $\mathrm{C} 2$ & 78 & $\mathrm{CH}_{3}$ rock out of plane \\
\hline TS2 & $645 \mathrm{i}$ & $\mathrm{C}-\mathrm{H}$ stretch \\
\hline C3 & 65 & $\mathrm{CH}_{2}-\mathrm{Fe}_{2}-\mathrm{Fe}$ bend \\
\hline TS3 & $832 \mathrm{i}$ & $\mathrm{H}-\mathrm{H}$ stretch \\
\hline $\mathrm{C} 4$ & 113 & $\mathrm{CH}_{2}-\mathrm{Fe}_{2}-\mathrm{Fe}$ bend \\
\hline \multicolumn{3}{|l|}{$M=13$} \\
\hline $\mathrm{Fe}_{4}$ & 150 & $\mathrm{Fe}-\mathrm{Fe}$ stretch \\
\hline $\mathrm{C} 1^{\prime}$ & 26 & Molecule rock out of plane \\
\hline TS1' & $951 \mathrm{i}$ & $\mathrm{C}-\mathrm{H}$ stretch \\
\hline C2' & 72 & $\mathrm{CH}_{3}$ rock out of plane \\
\hline TS2' & $685 i$ & $\mathrm{C}-\mathrm{H}$ stretch \\
\hline C3' & 85 & $\mathrm{CH}_{2}$ rock in plane \\
\hline TS3' & $773 \mathrm{i}$ & $\mathrm{H}-\mathrm{H}$ stretch \\
\hline C4' & 78 & $\mathrm{Fe}-\mathrm{Fe}_{2}-\mathrm{Fe}$ bend \\
\hline
\end{tabular}

